I premise that if we know anything about mechanics it is certain that a bird without working his wings cannot, either in still air or in a uniform horizontal wind, maintain his level indefinitely. For a short time such maintenance is possible at the expense of an initial relative velocity, but this must soon be exhausted. Whenever therefore a bird pursues his course for some time without working his wings, we must conclude either (I) that the course is not horizontal, (2) that the wind is not horizontal, or (3) that the wind is not uniform. It is probable that the truth is usually represented by (I) or (2); but the question I wish to raise is whether the cause suggested by (3) may not sometimes come into operation.

In NATURE, vol. xxiii. p. Io, Mr. S. E. Peal makes very distinct statements as to the soaring of pelicans and other Targe birds in Assam. The course is in large and nearly circular sweeps, and at each lap some Io or 20 feet of elevation is gained. When there is a wind, the birds may in this way "without once flapping the wings" rise from a height of 200 to a height of 8000 feet.

That birds do not soar when there is no wind is what we might suppose, but it is not evident how the existence of a wind helps the matter. If the wind were horizontal and uniform it certainly could not do so. As it does not seem probable that at a moderate distance from the ground there could be a sufficient vertical motion of the air to maintain the birds, we are led to inquire whether anything can be made of the difference of horizontal velocities which we know to exist at different levels.

In a uniform wind the available energy at the disposal of the bird depends upon his velocity relatively to the air about him. With only a moderate waste this energy can at any moment be applied to gain elevation, the gain of elevation being proportional to the loss of relative velocity squared. It will be convenient for the moment to ignore the waste referred to, and to suppose that the whole energy available remains constant, so that however the bird may ascend or descend, the relative velocity is that due to a fall from a certain level to the actual position, the certain level being of course that to which the bird might just rise by the complete sacrifice of relative velocity.

For distinctness of conception let us now suppose that above and below a certain plane there is a uniform horizontal wind, but that in ascending through this plane the velocity increases, and let us consider how a bird sailing somewhat above the plane of separation, and endowed with an initial relative velocity, might take advantage of the position in which he finds himself.

The first step is, if necessary, to turn round until the relative motion is to leeward, and then to drop gradually down through the plane of separation. In falling down to the level of the plane there is a gain of relative velocity, but this is of no significance for the present purpose, as it is purchased by the loss of elevation ; but in passing through the plane there is a really effective gain. In entering the lower stratum the actual velocity is indeed unaltered, but the velocity relatively to the surrounding air is increased. The bird must now wheel round in the lower stratum until the direction of motion is to windward, and then return to the upper stratum, in entering which there is a second increment of relative velocity. This process may evidently be refeated indefinitely; and if the successive increments of relative velocity squared are large enough to outweigh the inevitable waste which is in progress all the while, the bird may maintain his level, and even increase his available energy, without doing a stroke of work.

In nature there is of course no such abrupt transition as we have just now supposed, but there is usually a continuous increase of velocity with height. If this be sufficient, the bird may still take advantage of it to maintain or improve his position without doing work, on the principle that has been explained. For this purpose it is only necessary for him to descend while moving to leeward, and to ascend while moving to windward, the simplest mode of doing which is to describe circles on a plane. which inclines downwards to leeward. If in a complete lap the advantage thus obtained compensates the waste, the mean level will be maintained without expenditure of work; if there be a margin, there will be an outstanding gain of level susceptible of indefinite repetition.

$A$ priori, I should not have supposed the variation of velocity with height to be adequate for the purpose; but if the facts are correct, some explanation is badly wanted. Mr. Peal makes no mention of the circular sweeps being inclined to the horizon, a feature which is essential to the view suggested. It is just possible, however, that the point might escape attention not specially directed to it.

However the feat may be accomplished, if it be true that large birds can maintain and improve their levels without doing work, the prospect for human flight becomes less discouraging. Experimenters upon this subject would do well to limit their efforts for the present to the problem of gliding or sailing through the air. When a man can launch himself from an elevation and glide long distances before reaching the ground, an important step will have been gained, and until this can be done, it is very improbable that any attempt to maintain the level by expenditure of work can be successful. Large birds cannot maintain their levels in still air without a rapid horizontal motion, and it is easy to show that the utmost muscular work of a man is utterly inadequate with any possible wings to allow of his maintenance in a fixed position relatively to surrounding air. With a rapid horizontal motion, the thing may perhaps be possible, but for further information bearing upon this subject, I must refer to a paper on the resistance of fluids published in the Philosophical Magazine for December, 1876.

$$
\text { March } 22
$$

RAYLEIGH

\section{PHILIP CHRISTOPH ZELLER}

F NTOMOLOGY has just sustained an irreparable loss by the death of Prof. Zeller, which took place at Grünhof, near Stettin, on March 27, suddenly, from heart disease. Zeller was born on April 9, 1808, at Steinheim, in Württemburg. For many years he was attached to official educational establishments in Germany, especially at Glogau in Silesia, and Meseritz in Posen. While at the former place the honorary title of Professor was bestowed upon him by the Government on account of his eminent scientific researches, and some time afterwards he retired from official duties, and settled near Stettin, where much of his leisure was devoted to the Entomological Society that has its headquarters in that town, of which he was acting secretary, and of which Dr. C. A. Dohrn is president. Zeller's fame as an entomologist is more especially based upon his publications on Lepidoptera, more particularly of Europe, and chiefly on the smaller moths. His first recorded paper appeared in Oken's Isis for 1838 , and consisted of a critical determination of the Lepidoptera in Réaumur's "Memoirs," a prize essay, in which the author took first place. From that time a continuous stream of valuable papers by him appeared, and on the day of his death he was engaged in scientific work. It is utterly impossible to give here even the titles of his more important works. It is with regret that we are obliged to admit that the title of "entomologist" does not always enable us to take for granted that the entomologist is also a naturalist. Zeller was both, in the fullest acceptation of the terms. While his purely descriptive work is of the highest character, his investigations into the natural history of his subject were persistent, and he never ceased to deprecate the "slop-work" so painfully evident in the writings of some entomologists. For many years he made almost annual excursions in pursuit of his favourite science, especially in the Alps of Central 
Europe, and so long ago as I 844 a more extended tour in South Italy and Sicily. In this country he was so well known that British entomologists will feel that in his death they have lost one of themselves; it is nearly thirty-five years since he was elected an Honorary Member of the Entomological Society of London, and he was one of the editors of Mr. Stainton's magnificent "Natural History of the Tineina." There are those amongst us in this country who in Zeller's death have lost one of their dearest friends. Scientific entomology has lost one of its most shining lights.

R. MCLACHLAN

\section{THE GREAT INTERNATIONAL FISHERIES EXHIBITION}

HER MAJESTY THE QUEEN has recently appointed the I2th of May for the opening of the International Fisheries Exbibition, which an influential and energetic committee, under the active presidency of the Prince of Wales, has developed to a magnitude undreamt of by those concerned in its early beginnings. This magnitude is perhaps as great a matter of agreeable surprise to Mr. Birkbeck and its other Norwich founders as it will be to those who have very naturally become accustomed to class all specific exhibitions together upon a standard formed by the unfortunate annual exhibitions of which the public has, not without reason, grown weary.

The idea of an international Fisheries Exhibition arose out of the success of the show of British fishery held at Norwich a short time ago : and the president and executive of the latter formed the nucleus of the far more powerful body by whom the present enterprise has been brought about.

The buildings are well advanced towards completion, and will be finished long before the opening day; the exhibitors will, it is hoped, support the executive by sending in their goods in time, and thus all will be ready for the 12 th proximo.

The plan of the buildings embraces the whole of the twenty-two acres of the Horticultural Gardens: the upper half, left in its usual state of cultivation, will form a pleasant lounge and resting-place for visitcrs in the intervals of their study of the collections. This element of garden accommodation was one of the most attractive features at the Paris Exhibition of 1878 .

As the plan of the buildings is straggling and extended, and widely separates the classes, the most convenient mode of seeing the show will probably be found in going through the surrounding buildings first, and then taking the annexes as they occur.

On entering the main doors in the Exhibition Road, we pass through the Vestibule to the Council Room of the Royal Horticultural Society, which has been decorated for the reception of marine paintings, river subjects, and fish pictures of all sorts, by modern artists.

Leaving the Fine Arts behind, the principal builfing of the Exhibition is before us-that devoted to the deep sea fisheries of Great Britain. It is a handsome wooden structure $750 \mathrm{ft}$. in ler gth, $50 \mathrm{ft}$. wide, and $30 \mathrm{ft}$. at its greatest heigbt. The model of this, as well as of the other temporary wooden buildings, is the same as that of the annexes of the great Exhibition of 1862 .

On our left are the Dining Rooms with the Kitchens in the rear. The third room, set apart for cheap fish dinners (one of the features of the Exhibition), is to be decorated at the expense of the Baroness Burdett Coutts, and its walls are to be hung with pictures lent by the Fishmongers' Company, who have also furnished the requisite chairs and tables, and have made arrangements for a daily upply of cheap fish, while almost everything necessary to its maintenan se (forks, spoons, table-linen, \&c.), will be lent by various firms.
The apsidal building attached is to be devoted to lectures on the cooking of fish.

Having crossed the British Section, and turning to the right and passing by another entrance, we come upon what will be to all one of the most interesting features of the Exhibition, and to the scientific student of ichthyology a collection of paramount importance. We allude to the Western Arcade, in which are placed the Aquaria, which have in their construction given rise to more thoughtful care and deliberation than any other part of the works. On the right, in the bays, are the twenty large asphalt tanks, about $\mathrm{I} 2 \mathrm{ft}$. long, $3 \mathrm{ft}$. wide, and $3 \mathrm{ft}$. deep. These are the largest dimensions that the space at command will allow, but it is feared by some that they will be found somewhat confined for fast going fish. Along the wall on the left are ranged twenty smaller or table-tanks of slate, which vary somewhat in size; the ten largest are about $5 \mathrm{ft} .8 \mathrm{in}$. long, $2 \mathrm{ft} .9$ in. wide, and $\mathrm{Ift} .9$ in. deep.

In this Western Arcade will be found all the new inventions in fish culture-models of hatching, breeding and rearing establishments, apparatus for the transporting of fish, ova, models, and drawings of fish-passes and ladders, and representations of the development and growth of fish. The chief exhibitors are specialists, and are already well known to our readers. Sir James Gibson Maitland has taken an active part in the arrangement of this branch, and is himself one of the principal contributors.

In the north of the Arcade where it curves towards the Conservatory, will be shown an enormous collection of examples of stuffed fish, contributed by many of the prominent angling societies. In front of these on the counter will be ranged microscopic preparations of parasites, \&c., and a stand from the Norwich Exhibition of a fauna of fish and fish-eating birds.

Passing behind the Conservatory and down the Eastern Arcade-in which will be arranged Algx, Sponges, Mollusca, Star-fish, worms used for bait, insects which destroy spawn or which serve as food for fish, \&c.--on turning to the left, we find ourselves in the Fish Market, which will probably vie with the Aquaria on the other side in attracting popular attention. This model Billingsgate is to be divided into two parts, the one for the sale of fresh, the other of dried and cured fish.

Next in order come the two long iron sheds appropriated respectively to Life-boats and Machinery in motion. Then past the Royal Pavilion (the idea of which was doubtless taken from its prototype at the Paris Exhibition) to the southern end of the central block, which is shared by the Netherlands and Newfoundland; ju:t to the north of the former Belgium has a place.

While the Committee of the Netherlands was one of the earlie:t formed, Belgium only came in at the eleventh hour ; she will, however, owing to the zealous activity of Mr. Lenders, the Consul in I.ondon, send an important contribution worthy of her interest in the North Sea fisheries. We ought also to mention that New foundland is among those colonies which have shown great energy, and she may be expected to send a large collection.

Passing northward we come to Sweden and Norway, with Chili between them. These two countries were, like the Netherlands, early in freparing to participate in the Exhibition. Each has had its own Committee, which has been working hard since early in 1882 .

Parallel to the Scandinavian section is that devoted to Canada and the United States. While the American Government has frei hted a ship with specimens expected daily, the former has entered heart and soul into the friendly rivalry, and will occupy an equal space---ten thousand square feet.

In the Northern Transept will be placed the inland fisheries of the United Kingdom. At each end of the building is aptly inclosed a basin formerly standing in the gardens: and over the eastern one will be erected the 